Review

\title{
Carbon Nanomaterials: Efficacy and Safety for Nanomedicine
}

Takuya Yamashita ${ }^{1,2, \dagger}$, Kohei Yamashita ${ }^{1,2, \dagger}$, Hiromi Nabeshi ${ }^{1,2}$, Tomoaki Yoshikawa ${ }^{1,2}$, Yasuo Yoshioka ${ }^{1,2,3, *}$, Shin-ichi Tsunoda ${ }^{2,3,4}$ and Yasuo Tsutsumi ${ }^{1,2,3, *}$

1 Laboratory of Toxicology and Safety Science, Graduate School of Pharmaceutical Sciences, Osaka University, 1-6 Yamadaoka, Suita, Osaka 565-0871, Japan; E-Mails: t-yamashita@nibio.go.jp (T.Y.); yamasita@phs.osaka-u.ac.jp (K.Y.); nabeshi@phs.osaka-u.ac.jp (H.N.); tomoaki@phs.osaka-u.ac.jp (T.Y.)

2 Laboratory of Biopharmaceutical Research, National Institute of Biomedical Innovation, 7-6-8 Saito-Asagi, Ibaraki, Osaka 567-0085, Japan; E-Mail: tsunoda@nibio.go.jp

3 The Center for Advanced Medical Engineering and Informatics, Osaka University, 1-6 Yamadaoka, Suita, Osaka 565-0871, Japan

4 Laboratory of Biomedical Innovation, Graduate School of Pharmaceutical Sciences, Osaka University, 1-6 Yamadaoka, Suita, Osaka 565-0871, Japan

$\dagger$ These authors contributed equally to the work.

* Authors to whom correspondence should be addressed; E-Mails: yasuo@phs.osaka-u.ac.jp (Y.Y.); ytsutsumi@phs.osaka-u.ac.jp (Y.T.); Tel.: +81-6-6879-8233; Fax: +81-6-6879-8233.

Received: 16 December 2011; in revised form: 11 February 2012 / Accepted: 15 February 2012 / Published: 21 February 2012

Abstract: Carbon nanomaterials, including fullerenes, carbon nanohorns, and carbon nanotubes, are increasingly being used in various fields owing to these materials' unique, size-dependent functions and physicochemical properties. Recently, because of their high variability and stability, carbon nanomaterials have been explored as a novel tool for the delivery of therapeutic molecules including peptide and nucleic acid cancer drugs. However, insufficient information is available regarding the safety of carbon nanomaterials for human health, even though such information is vital for the development of safe and effective nanomedicine technologies. In this review, we discuss currently available information regarding the safety of carbon nanomaterials in nanomedicine applications, including information obtained from our own studies; and we discuss types of carbon nanomaterials that demonstrate particular promise for safe nanomedicine technologies. 
Keywords: nanomedicine; carbon nanomaterials; fullerenes; carbon nanohorns; carbon nanotubes; drug delivery; nano safety science

\section{Introduction}

Advances in nanotechnology have led to the recent development of many nanomaterials, including nanoscale silica particles, titanium dioxide nanoparticles, and carbon nanomaterials [1-4]. Nanomaterials, which are generally classified as materials with feature sizes smaller than $100 \mathrm{~nm}$, have remarkably impacted various fields of study because of the desirable properties (e.g., enhanced electrical conductivity, tensile strength, and chemical reactivity) imparted by their increased surface area per unit weight compared with that of their bulk-scale counterparts $[5,6]$. Nanomaterials are already being applied in electronics [1], foods [2], and cosmetics [3]. Furthermore, in basic research for development of new drugs, nanomaterials are expected to open novel avenues for the treatment of human diseases owing to their unique physicochemical properties [4].

Carbon nanomaterials, including fullerenes, carbon nanohorns (CNHs), and carbon nanotubes (CNTs), have been used as carriers in drug delivery and other applications [7]. Carbon nanomaterials with carbon cage and graphene structures have many technological advantages such as facile modification by functional groups [8-10], high carrier capacity [11,12], high chemical stability [13,14], and feasibility of incorporating both hydrophilic and hydrophobic substances $[15,16]$ (Table 1). These characteristics, which are essential for the development of drug-delivery carriers, make carbon nanomaterials promising for nanomedicine applications.

Table 1. Basic physicality of carbon nanomaterials.

\begin{tabular}{llll}
\hline & Fullerenes & CNHs & CNTs \\
\hline Year of discovery & 1985 & 1998 & 1991 \\
\hline \multirow{2}{*}{ Discoverer } & $\begin{array}{l}\text { H.W. Kroto } \\
\text { R.F. Curl } \\
\text { R.E. Smalley }\end{array}$ & S. Iijima & S. Iijima \\
\hline $\begin{array}{l}\text { Size } \\
\text { Diameter }\end{array}$ & $1 \mathrm{~nm}$ & & \\
$\quad-$ & $2-4 \mathrm{~nm}$ & $0.4-70 \mathrm{~nm}$ \\
Length & sphere & $40-70 \mathrm{~nm}$ & $1 \mu \mathrm{m}-2.5 \mathrm{~mm}$ \\
\hline Shape & Cosmetics & horn & fiber \\
Practical use & $\begin{array}{l}\text { Lubricity agent } \\
\text { Semiconductor }\end{array}$ & Fuel battery & $\begin{array}{l}\text { Semiconductor } \\
\text { Car parts } \\
\text { Sports goods }\end{array}$ \\
\hline
\end{tabular}

Though highly promising, these carbon nanomaterials are in an early phase of development. Therefore, information regarding their safety is not sufficient for the development of medically sound and nontoxic technologies. Because nanomaterials' physicochemical properties often differ substantially from those of their bulk counterparts, as mentioned above, there are concerns that carbon nanomaterials may exhibit unexpected side effects. In addition, recent reports have shown that pristine CNTs might induce mesothelioma-like lesions in mice, similar to those induced by asbestos [17-19]. On the other 
hand, Muller et al. showed that pristine CNTs induce no mesothelioma formation in a 2-year in vivo study [20]. Therefore, more information about the safety of nanomaterials needs to be collected.

In this review, we discuss currently available information about the safety of carbon nanomaterials for nanomedicine applications, including information obtained from our own previous studies. We also discuss types of carbon nanomaterials that demonstrate particular promise for safe nanomedicine technologies.

\section{Utility of Carbon Nanomaterials for Nanomedicine}

\subsection{Fullerenes}

Fullerenes have attracted considerable attention in various fields of science [21]. Fullerenes are composed entirely of carbon in the form of a hollow sphere, ellipsoid, or tube. Spherical fullerenes are also referred to as buckyballs. An important property of the fullerene molecule is their high symmetry. There are 120 symmetry operations, such as rotation around an axis and reflection in a plane. Fullerenes belong to the class of inorganic nanoparticles and show high bioavailability due to their small size $(\sim 1 \mathrm{~nm})$. Owing to their small size, fullerenes can penetrate various tissues and organelles that materials with submicron size cannot penetrate. For example, Foley et al. reported that fullerenes can cross the COS-7 cell membrane and bind to the mitochondria [22], demonstrating that fullerenes have utility as intracellular carriers. Furthermore, fullerenes' capability to act as drug-delivery carriers for low-molecular-weight compounds and oligonucleotides has been demonstrated [23]. For example, conjugates composed of fullerenes and paclitaxel have exhibited the potential to provide slow release of the drug and have exhibited significant anti-cancer activity in cell cultures [24]. Moreover, Maeda-Mamiya et al. reported effective gene delivery in vivo using water-soluble fullerenes [25]. In that study, conjugates consisting of cationic tetraamino fullerenes and an insulin-gene-expressing plasmid complex were injected intravenously into C57/BL6 mice. Insulin gene expression was detected in the lung, liver, and spleen. Plasma insulin levels in the insulin gene group of mice were significantly higher than those in a control group. Both of these studies demonstrate that fullerenes may act as drug- and gene-delivery carriers. Furthermore, because fullerenes are strong anti-oxidants, they have been used as neuroprotective [26,27] and anti-inflammatory agents [28]. Thus, if fullerenes can be controllably manipulated, they could be used to treat various diseases.

\section{2. $\mathrm{CNHs} / \mathrm{CNTS}$}

CNHs and CNTs based on the structure of graphene are also regarded as drug-delivery carriers [29,30]. CNHs and CNTs are differentiated from each other by their shape and size (Table 1). Furthermore, CNHs and CNTs can be classified as possessing either single- or multi-walled (SW or MW) structures. This review cites several reports on the use of SWCNHs and SWCNTs as drug-delivery carriers. SWCNHs have plenty of inner spaces. Through these holes, various molecules such as low-molecular-weight compounds or nucleic acids can enter the hollow interior of the SWCNHs. SWCNHs also can regulate the sustained release of drugs from their interior for drug-delivery applications. For example, the release rate of cisplatin (CDDP), a chemotherapy drug that can be incorporated into oxidized SWCNHs, has been regulated by controlling solvent composition. The release of CDDP from the SWCNHs is slower in water and a culture medium than in 
phosphate-buffered saline, and the CDDP released from SWCNHs in the former solvent effectively kills human lung-cancer cells [11].

SWCNTs also have been demonstrated to be amenable for drug delivery. SWCNT-siRNA conjugates have been efficiently transported to human T-cells and primary cells, which are inert to commercially available liposome-based nonviral vectors, and have silenced a specific gene in those cells [31]. In cancer therapy, SWCNT-based tumor-targeted drug-delivery system (DDS) has already been developed by several investigators [32,33]. SWCNT-anticancer-drug conjugates also have shown higher efficacy in suppressing tumor growth than clinical anticancer drugs alone in various cancer models [32,33]. These therapeutic effects were induced by accumulation of the conjugates in tumor. Collectively, these results clearly indicate the potential applications of SWCNHs and SWCNTs in cancer-targeted drug delivery and sustained release [34].

\subsection{Suitable Modification of Carbon Nanomaterials for DDS}

Accumulation at a targeted location is important in DDS. Carbon-nanomedicine-based cancer treatment systems generally function by means of either active targeting or passive targeting. In active-targeting DDS for cancer treatment, the search for cancer-specific targets is important. SWCNTs modified with antibodies, folate, arginine-glycine-aspartic acid (rgd) peptide, and epidermal growth factors have been useful for active targeting of tumor tissue [35-38]. Ruggiero et al. reported that antibody-modified SWCNTs accumulate in tumor tissue in a murine xenograft model of human colon adenocarcinoma [39]. However, these anti-cancer effects are not enough to enable drug development because these targets do not express specifically in tumor. In recent years, novel targets have been identified by using "-omics" approaches such as proteomics, genomics, and metabolomics [40-42]. Proteomics-based analysis is currently a promising approach for identifying biomarker proteins for use in drug development because these proteins directly regulate the onset and progression of diseases. However, proteomics-based analysis can yield many potential candidate biomarker proteins that are over- or under-expressed in diseased tissues, and these candidates must be efficiently screened to identify appropriate targets. Toward this end, we have developed an "antibody proteomics system" that facilitates the screening of biomarker proteins from many candidates by rapid preparation of cross-reacting antibodies using phage antibody library technology. The system is an efficient method for screening tumor-related biomarker proteins to identify novel targets [43].

In passive-targeting DDS for cancer treatment, improvement of drug retention in blood is important because the reticulo-endothelial system and kidney work as the barrier against foreign particles in vivo. Covalent conjugation of polyethylene glycol (PEG) to a carrier's surface, referred to as "PEGylation" is a promising strategy to improve retention of various nanomaterials in the blood [44]. PEGylation can prolong the plasma half-life and alter the tissue distribution of the nanomaterial conjugates compared with their non-PEGylated forms, which typically clear the body through the reticulo-endothelial system in vivo. The extended circulating lifetime of PEGylated conjugates in blood induces an enhanced permeability and retention effect, which is based on the leaky nature of tumor blood vessels, resulting in increased delivery of the conjugates to tumor tissue. As an example, Yang et al. investigated the long-term in vivo biodistribution of nanoscale graphene sheets functionalized with PEG and systematically examined the potential toxicity of graphene over time [45]. On the other hand, from the 
aspect of effectivity and safety, CNTs kinetics is important for drug development. Singh et al. describes the pharmacokinetic parameters of intravenous administered functionalized SWCNTs relevant for various therapeutic and diagnostic applications [46]. It shows that functionalized (water-soluble) SWCNTs can, in fact, be excreted via the renal route. In summary, to obtain highly effective and nontoxic carbon nanomaterial DDS for cancer treatment, it is necessary to control three factors: (1) size; (2) the ability to target the molecules to tumors and (3) clearance through the reticulo-endothelial system and kidney.

\subsection{Other Application of CNTs in Medicine}

As mentioned above, CNTs have been explored as a novel tool for the delivery of therapeutic molecules including peptide, nucleic acid and cancer drugs. On the other hand, certain types of CNTs have been reported to possibly help cancer diagnosis and other application $[47,48]$. Photoacoustic imaging proposes higher spatial resolution and permits deeper tissues to be imaged compared with most optical imaging techniques. Zerda et al. [47] showed plain SWCNTs conjugated with cyclic Arg-Gly-Asp (RGD) peptides can be used as a agent for photoacoustic imaging of tumors. This report indicates SWCNTs is possibly useful for cancer diagnosis. Additionally, Tosun et al. suggested collagen conjugated SWCNTs show the potential for enhanced electrical activity. These SWCNTs have been shown positive in vitro biocompatibility results offering further evidence that SWCNT-based materials have an important role in neuronal regeneration [48]. Neurodegenerative disorders including Parkinson's and Alzheimer's diseases, amyotrophic lateral sclerosis are rapidly increasing as the population ages. The field of nanomedicine promises revolutionary advances to the diagnosis and treatment of devastating human diseases [48].

\section{Safety of Carbon Nanomaterials}

\subsection{Hazard Assessment}

Carbon nanomaterials are among the most promising nanomedicines. However, information about the safety of carbon nanomaterials is still fragmentary, and ensuring their safety is of utmost importance to protect human health. In this section, we focus on the safety of CNTs specifically, because some studies have reported that CNTs have higher toxicity than fullerenes and CNHs [49].

Parameters such as structure, size distribution, surface area, surface chemistry, surface charge, and agglomeration state as well as purity of the samples, have considerable impact on the reactivity of CNTs. Some studies have reported that certain types of SW or MW CNTs are cytotoxic and genotoxic in vitro, so public concern about the potential risk of CNTs to human health has risen [50-52]. In fact, recent reports have indicated that certain types of CNTs might induce mesothelioma-like lesions in mice, in a manner similar to that observed for mesothelioma induced by asbestos [53-55]. Takagi et al. showed that intraperitoneally administered pristine MWCNTs induce mesothelioma in the p53 (+/-) mouse carcinogenesis model, probably due to the MWCNTs' resemblance to asbestos in size and shape and to their biopersistency [17]. Poland et al. also observed asbestos-like pathogenic behavior of long pristine MWCNTs associated with their needle-like fiber shape and established a structure-activity relationship based on the length of the MWCNTs [19]. These studies revealed that the propensity of 
long MWCNT fibers to produce inflammation and fibrosis in the peritoneal cavity is similar to, or greater than, that of long asbestos fibers. In contrast, neither short asbestos fibers nor short tangled MWCNTs cause any significant inflammation [19]. These results suggest that physical properties, such as length, diameter and physico-chemical properties, might impact the safety of pristine CNTs [56]. However, these studies were based on the administration of extremely high doses of MWCNTs via peritoneal injection. In contrast, Shvedova et al. showed that pristine MWCNTs enhanced acute inflammation and pulmonary injury with delayed bacterial clearance after aspiration or inhalation of MWCNTs [57,58]. In the future, it is needed to examine the study relevant to the human occupational exposure situation.

There are a few reports that examine the mechanisms of CNT toxicity [59-61]. One important underlying factor that influences the safety of long fibers is the failure of macrophage cells to completely enclose them. This failure, termed incomplete or "frustrated" phagocytosis, can induce inflammation [19]. Migliore et al. showed that long rigid MWCNTs appear to form fiber-like aggregates or structures that are too long to be phagocytosed by macrophage cells, thus resulting in reactive oxygen species (ROS) production [62,63], which contributes to NACHT domain-, leucine-rich repeat-, and pyrin domain-containing protein 3 (NLRP3) activation [64,65]. Palomaki et al. demonstrated that the NLRP3 inflammasome was essential for long, needle-like CNTs and asbestos to induce IL-1 $\beta$ secretion [65]. Moreover, it was noted that CNT-induced NLRP3 inflammasome activation depended on ROS production [65]. Clarification of the mechanism of inflammation induced by CNTs might lead to the development of safe carbon nanomedicine technologies.

Although some studies have reported concern about the safety of CNTs as mentioned above, other studies have reported that certain types of CNTs are safe materials for nanomedicine. Yang et al. demonstrated that after intravascular injection of pristine SWCNTs, mice did not show stress or symptoms of abnormality, such as lethargy, anorexia, or changes in body weight [66]. Furthermore, Wick et al. showed that the cytotoxicity of purified rope-like agglomerated SWCNTs was lower than that of well-dispersed SWCNTs [67]. In addition to the fiber-like structure of CNTs, the amount of metal contaminants such as iron or nickel found in the CNTs may contribute to the nanomaterials' potential carcinogenicity by accelerating the generation of ROS [68-70]. Moreover, in preparation for drug development, it is important to examine the influence of the oxidative debris on CNTs [14,71-73]. It is an emergent and key point during purification and functionalization of carbon nanostructure. These studies suggest that the safety of CNTs is determined not only by physical properties but also by a wide variety of factors such as method of administration, dispersability, and presence of metal contaminants. How much these factors contribute to the safety of CNTs remains unknown, however. We believe that the information obtained by these safety studies might be useful for ensuring the safety of CNTs.

\subsection{Biological Behavior of CNTs}

Evaluation of in vivo kinetics is important for assessing the safety of nanomedicine technologies. In this section, studies about the behavior of CNTs in the body are described. Ruggiero et al. showed that intravascularly injected pristine SWCNTs favor liver accumulation and hepatobiliary excretion over kidney accumulation and renal excretion [39]. In addition, several studies have investigated pulmonary 
effects subsequent to instillation, aspiration, and inhalation of pristine SWCNTs [57]. These reports showed that short and small tangles of SWCNTs that deposit subpleurally migrate to the pleural space and exit in the flow of pleural fluid through the stomata, where they follow the lymphatic drainage to the mediastinal lymph nodes [60,74]. In addition, long carbon nanotubes also reach the pleural space but cannot negotiate the stomata, and so they are retained in the pleural space, where they cause inflammation and potentially long-term disease $[60,74]$.

Kagan et al. showed that hypochlorite and reactive radical intermediates of the human neutrophil enzyme myeloperoxidase catalyze the biodegradation of carboxylated SWCNTs in vitro, in neutrophils and to a lesser degree in macrophages [75]. Importantly, the biodegraded nanotubes do not generate an inflammatory response when aspirated into the lungs of mice [75]. In addition, Liu et al. have reported that the biodurability of SWCNTs depends on surface functionalization [76]. Based on these findings, strategies for mitigating the pro-inflammatory effects of these nanomaterials in occupational settings may be developed.

Furthermore, information about toxicokinetics (absorption, distribution, metabolism and elimination) also should be obtained for the development of safe CNTs.

\subsection{Development of Safe Nanomaterials}

We have discussed above how nanomaterials can serve as useful nanomedicine technologies and have also highlighted the importance of considering these nanomaterials' safety for such applications. In this section, we examine the current status of the development of safe and effective nanomaterials for nanomedicine. In our own studies, we have established relationships between the physical properties and safety of CNTs. Our data showed that pristine thin MWCNTs and SWCNTs do not induce genetic damage in vitro and inflammation in vivo [77]. These data indicate that physical properties such as particle length and width might influence the safety of CNTs. In addition, Nagai et al. suggested the large-diameter or tangled MWCNTs are less toxic, less inflammogenic, and less carcinogenic than untangled MWCNTs [56]. These results suggest that control of the diameter of CNTs could be used to develop CNTs that are safe for human health.

Furthermore, in addition to being critically important for the detection of biomolecules, the surface properties of nanomaterials also can modulate the materials' safety. Recent studies have shown that functionalization of CNTs with carboxyl or amino surface groups can affect the CNTs' toxicity [78]. Thus, regulation both of particle size and of surface properties is considered important for research leading to the development of safe nanomedicine technologies.

In fact, our previous study showed that nanoscale silica particles, which we expected to be useful as drug-delivery carriers, display different intracellular localization compared with submicron- and micro-scale silica particles and induce a greater cytotoxic response to mouse macrophage cell line [79]. We have also shown that nanoscale silica particles induce certain cellular responses, such as ROS generation and DNA damage to human keratinocyte cell line [80]. These results indicate that particle size could influence the silica particles' safety for applications in nanomedicine. In addition, we have shown that surface modification of silica particles with functional groups, such as amino or carboxyl groups, suppresses toxic biological effects of silica particles including inflammatory responses and ROS production [81]. A recent study demonstrated that nanomaterials become coated with serum 
proteins and induce different cellular responses from intact particles by binding to proteins [82]. In addition, different surface characteristics, such as surface charge, influence the binding affinities of proteins to nanomaterials $[82,83]$. In fact, Gasser et al. showed that functionalization of MWCNTs have the potential to alter the MWCNTs blood plasma protein coating in biological systems $[84,85]$. These results indicate that particle size or surface properties of carbon nanomaterials can affect their safety, and that control of these physical properties can be used to advance the development of safe nanomaterials.

\section{Conclusions}

The unique physicochemical properties of carbon nanomaterials allow them to incorporate targeting ligands, chemotherapeutic drugs, and many other therapeutic agents that have great potential for cancer-targeted therapy. However, owing to the large number of factors that influence the kinetics of drug release from nanomaterials, as well as their safety for human health, insufficient information is available on these two important subjects. Factors that influence the safety of and kinetics of drug release from nanomaterials include their shape, length, and dispersability, as well as the presence of metal contaminants. A detailed understanding of the pharmacological and toxicological properties of carbon nanomaterials, as well as a balanced evaluation of their risks and benefits to human health, is required before they can be recommended for routine clinical use. We believe that a detailed safety analysis of carbon nanomaterials will be invaluable for the design of safe nanomedicine technologies.

\section{Acknowledgements}

This study was supported in part by Grants-in-Aid for Scientific Research from JSPS; by Health Labour Sciences Research Grants from the Ministry of Health, Labor and Welfare of Japan; by a Global Environment Research Fund from Minister of the Environment; by Food Safety Commission; by The Cosmetology Research Foundation; by The Smoking Research Foundation; by The Takeda Science Foundation.

\section{References}

1. Konstantatos, G.; Sargent, E.H. Nanostructured materials for photon detection. Nat. Nanotechnol. 2010, 5, 391-400.

2. Augustin, M.A.; Sanguansri, P. Nanostructured materials in the food industry. Adv. Food Nutr. Res. 2009, 58, 183-213.

3. Bowman, D.M.; van Calster, G.; Friedrichs, S. Nanomaterials and regulation of cosmetics. Nat. Nanotechnol. 2010, 5, 92.

4. Petros, R.A.; DeSimone, J.M. Strategies in the design of nanoparticles for therapeutic applications. Nat. Rev. Drug Discov. 2010, 9, 615-627.

5. Stern, S.T.; McNeil, S.E. Nanotechnology safety concerns revisited. Toxicol. Sci. 2008, 101, 4-21.

6. Lacerda, L.; Bianco, A.; Prato, M.; Kostarelos, K. Carbon nanotubes as nanomedicines: From toxicology to pharmacology. Adv. Drug Deliv. Rev. 2006, 58, 1460-1470. 
7. Tiwari, A.K.; Gajbhiye, V.; Sharma, R.; Jain, N.K. Carrier mediated protein and peptide stabilization. Drug Deliv. 2010, 17, 605-616.

8. Martinez-Loran, E.; Alvarez-Zauco, E.; Basiuk, V.A.; Basiuk, E.V.; Bizarro, M. Fullerene thin films functionalized by 1,5-diaminonaphthalene: Preparation and properties. J. Nanosci. Nanotechnol. 2011, 11, 5569-5573.

9. Ci, L.; Ajayan, P.M. Modifying surface structure to tune surface properties of vertically aligned carbon nanotube films. J. Nanosci. Nanotechnol. 2010, 10, 3854-3859.

10. Velamakanni, A.; Magnuson, C.W.; Ganesh, K.J.; Zhu, Y.; An, J.; Ferreira, P.J.; Ruoff, R.S. Site-specific deposition of Au nanoparticles in CNT films by chemical bonding. ACS Nano 2010, 4, 540-546.

11. Ajima, K.; Yudasaka, M.; Murakami, T.; Maigne, A.; Shiba, K.; Iijima, S. Carbon nanohorns as anticancer drug carriers. Mol. Pharm. 2005, 2, 475-480.

12. Klumpp, C.; Kostarelos, K.; Prato, M.; Bianco, A. Functionalized carbon nanotubes as emerging nanovectors for the delivery of therapeutics. Biochim. Biophys. Acta 2006, 1758, 404-412.

13. Rodriguez-Zavala, J.G.; Guirado-Lopez, R.A. Stability of highly OH-covered C60 fullerenes: Role of coadsorbed $\mathrm{O}$ impurities and of the charge state of the cage in the formation of carbon-opened structures. J. Phys. Chem. A 2006, 110, 9459-9468.

14. Heister, E.; Lamprecht, C.; Neves, V.; Tilmaciu, C.; Datas, L.; Flahaut, E.; Soula, B.; Hinterdorfer, P.; Coley, H.M.; Silva, S.R.; McFadden, J. Higher dispersion efficacy of functionalized carbon nanotubes in chemical and biological environments. ACS Nano 2010, 4, 2615-2626.

15. Iohara, D.; Hirayama, F.; Higashi, K.; Yamamoto, K.; Uekama, K. Formation of stable hydrophilic C60 nanoparticles by 2-hydroxypropyl-beta-cyclodextrin. Mol. Pharm. 2011, 8, $1276-1284$.

16. Weiss, D.R.; Raschke, T.M.; Levitt, M. How hydrophobic buckminsterfullerene affects surrounding water structure. J. Phys. Chem. B 2008, 112, 2981-2990.

17. Takagi, A.; Hirose, A.; Nishimura, T.; Fukumori, N.; Ogata, A.; Ohashi, N.; Kitajima, S.; Kanno, J. Induction of mesothelioma in $\mathrm{p} 53+/-$ mouse by intraperitoneal application of multi-wall carbon nanotube. J. Toxicol. Sci. 2008, 33, 105-116.

18. Sakamoto, Y.; Nakae, D.; Fukumori, N.; Tayama, K.; Maekawa, A.; Imai, K.; Hirose, A.; Nishimura, T.; Ohashi, N.; Ogata, A. Induction of mesothelioma by a single intrascrotal administration of multi-wall carbon nanotube in intact male Fischer 344 rats. J. Toxicol. Sci. 2009, 34, 65-76.

19. Poland, C.A.; Duffin, R.; Kinloch, I.; Maynard, A.; Wallace, W.A.; Seaton, A.; Stone, V.; Brown, S.; Macnee, W.; Donaldson, K. Carbon nanotubes introduced into the abdominal cavity of mice show asbestos-like pathogenicity in a pilot study. Nat. Nanotechnol. 2008, 3, 423-428.

20. Muller, J.; Delos, M.; Panin, N.; Rabolli, V.; Huaux, F.; Lison, D. Absence of carcinogenic response to multiwall carbon nanotubes in a 2-year bioassay in the peritoneal cavity of the rat. Toxicol. Sci. 2009, 110, 442-448.

21. Mateo-Alonso, A.; Guldi, D.M.; Paolucci, F.; Prato, M. Fullerenes: Multitask components in molecular machinery. Angew. Chem. Int. Ed. Engl. 2007, 46, 8120-8126. 
22. Foley, S.; Crowley, C.; Smaihi, M.; Bonfils, C.; Erlanger, B.F.; Seta, P.; Larroque, C. Cellular localisation of a water-soluble fullerene derivative. Biochem. Biophys. Res. Commun. 2002, 294, 116-119.

23. Sitharaman, B.; Zakharian, T.Y.; Saraf, A.; Misra, P.; Ashcroft, J.; Pan, S.; Pham, Q.P.; Mikos, A.G.; Wilson, L.J.; Engler, D.A. Water-soluble fullerene (C60) derivatives as nonviral gene-delivery vectors. Mol. Pharm. 2008, 5, 567-578.

24. Zakharian, T.Y.; Seryshev, A.; Sitharaman, B.; Gilbert, B.E.; Knight, V.; Wilson, L.J. A fullerene-paclitaxel chemotherapeutic: Synthesis, characterization, and study of biological activity in tissue culture. J. Am. Chem. Soc. 2005, 127, 12508-12509.

25. Maeda-Mamiya, R.; Noiri, E.; Isobe, H.; Nakanishi, W.; Okamoto, K.; Doi, K.; Sugaya, T.; Izumi, T.; Homma, T.; Nakamura, E. In vivo gene delivery by cationic tetraamino fullerene. Proc. Natl. Acad. Sci. USA 2010, 107, 5339-5344.

26. Chen, T.; Li, Y.Y.; Zhang, J.L.; Xu, B.; Lin, Y.; Wang, C.X.; Guan, W.C.; Wang, Y.J.; Xu, S.Q. Protective effect of C(60)-methionine derivate on lead-exposed human SH-SY5Y neuroblastoma cells. J. Appl. Toxicol. 2011, 31, 255-261.

27. Huang, S.S.; Tsai, S.K.; Chih, C.L.; Chiang, L.Y.; Hsieh, H.M.; Teng, C.M.; Tsai, M.C. Neuroprotective effect of hexasulfobutylated $\mathrm{C} 60$ on rats subjected to focal cerebral ischemia. Free Radic. Biol. Med. 2001, 30, 643-649.

28. Huang, S.T.; Ho, C.S.; Lin, C.M.; Fang, H.W.; Peng, Y.X. Development and biological evaluation of $\mathrm{C}(60)$ fulleropyrrolidine-thalidomide dyad as a new anti-inflammation agent. Bioorg. Med. Chem. 2008, 16, 8619-8626.

29. Zhu, S.; Xu, G. Single-walled carbon nanohorns and their applications. Nanoscale 2010, 2, 2538-2549.

30. Awasthi, K.; Srivastava, A.; Srivastava, O.N. Synthesis of carbon nanotubes. J. Nanosci. Nanotechnol. 2005, 5, 1616-1636.

31. Liu, Z.; Winters, M.; Holodniy, M.; Dai, H. siRNA delivery into human T cells and primary cells with carbon-nanotube transporters. Angew. Chem. Int. Ed. Engl. 2007, 46, 2023-207.

32. Zhang, X.; Meng, L.; Lu, Q.; Fei, Z.; Dyson, P.J. Targeted delivery and controlled release of doxorubicin to cancer cells using modified single wall carbon nanotubes. Biomaterials 2009, 30, 6041-6047.

33. Liu, Z.; Sun, X.; Nakayama-Ratchford, N.; Dai, H. Supramolecular chemistry on water-soluble carbon nanotubes for drug loading and delivery. ACS Nano 2007, 1, 50-56.

34. Pardasani, D.; Kanaujia, P.K.; Purohit, A.K.; Shrivastava, A.R.; Dubey, D.K. Magnetic multi-walled carbon nanotubes assisted dispersive solid phase extraction of nerve agents and their markers from muddy water. Talanta 2011, 86, 248-255.

35. Ou, Z.; Wu, B.; Xing, D.; Zhou, F.; Wang, H.; Tang, Y. Functional single-walled carbon nanotubes based on an integrin alpha $\mathrm{v}$ beta 3 monoclonal antibody for highly efficient cancer cell targeting. Nanotechnology 2009, 20, 105102.

36. Cheng, W.; Ding, L.; Lei, J.; Ding, S.; Ju, H. Effective cell capture with tetrapeptide-functionalized carbon nanotubes and dual signal amplification for cytosensing and evaluation of cell surface carbohydrate. Anal. Chem. 2008, 80, 3867-3872. 
37. Lu, Y.J.; Wei, K.C.; Ma, C.C.; Yang, S.Y.; Chen, J.P. Dual targeted delivery of doxorubicin to cancer cells using folate-conjugated magnetic multi-walled carbon nanotubes. Colloids Surf. B. 2012, 89, 1-9.

38. Wang, C.H.; Chiou, S.H.; Chou, C.P.; Chen, Y.C.; Huang, Y.J.; Peng, C.A. Photothermolysis of glioblastoma stem-like cells targeted by carbon nanotubes conjugated with CD133 monoclonal antibody. Nanomedicine 2011, 7, 69-79.

39. Ruggiero, A.; Villa, C.H.; Bander, E.; Rey, D.A.; Bergkvist, M.; Batt, C.A.; Manova-Todorova, K.; Deen, W.M.; Scheinberg, D.A.; McDevitt, M.R. Paradoxical glomerular filtration of carbon nanotubes. Proc. Natl. Acad. Sci. USA 2010, 107, 12369-12374.

40. Geng, R.; Li, Z.; Li, S.; Gao, J. Proteomics in pancreatic cancer research. Int. J. Proteomics 2011, 2011,365350 .

41. Taylor, B.S.; Ladanyi, M. Clinical cancer genomics: How soon is now? J. Pathol. 2011, 223, 318-326.

42. Bathen, T.F.; Sitter, B.; Sjobakk, T.E.; Tessem, M.B.; Gribbestad, I.S. Magnetic resonance metabolomics of intact tissue: A biotechnological tool in cancer diagnostics and treatment evaluation. Cancer Res. 2010, 70, 6692-6696.

43. Imai, S.; Nagano, K.; Yoshida, Y.; Okamura, T.; Yamashita, T.; Abe, Y.; Yoshikawa, T.; Yoshioka, Y.; Kamada, H.; Mukai, Y.; et al. Development of an antibody proteomics system using a phage antibody library for efficient screening of biomarker proteins. Biomaterials 2010, 32, 162-169.

44. Fang, J.; Sawa, T.; Maeda, H. Factors and mechanism of "EPR" effect and the enhanced antitumor effects of macromolecular drugs including SMANCS. Adv. Exp. Med. Biol. 2003, 519, $29-49$.

45. Yang, K.; Wan, J.; Zhang, S.; Zhang, Y.; Lee, S.T.; Liu, Z. In vivo pharmacokinetics, long-term biodistribution, and toxicology of PEGylated graphene in mice. ACS Nano 2010, 5, 516-522.

46. Singh, R.; Pantarotto, D.; Lacerda, L.; Pastorin, G.; Klumpp, C.; Prato, M.; Bianco, A.; Kostarelos, K. Tissue biodistribution and blood clearance rates of intravenously administered carbon nanotube radiotracers. Proc. Natl. Acad. Sci. USA 2006, 103, 3357-3362.

47. De la Zerda, A.; Zavaleta, C.; Keren, S.; Vaithilingam, S.; Bodapati, S.; Liu, Z.; Levi, J.; Smith, B.R.; Ma, T.J.; Oralkan, O.; et al. Carbon nanotubes as photoacoustic molecular imaging agents in living mice. Nat. Nanotechnol. 2008, 3, 557-562.

48. Tosun, Z.; McFetridge, P.S. A composite SWNT-collagen matrix: Characterization and preliminary assessment as a conductive peripheral nerve regeneration matrix. J. Neural Eng. 2010, 7, 066002.

49. Uo, M.; Akasaka, T.; Watari, F.; Sato, Y.; Tohji, K. Toxicity evaluations of various carbon nanomaterials. Dent. Mater. J. 2011, 30, 245-263.

50. Vankoningsloo, S.; Piret, J.P.; Saout, C.; Noel, F.; Mejia, J.; Zouboulis, C.C.; Delhalle, J.; Lucas, S.; Toussaint, O. Cytotoxicity of multi-walled carbon nanotubes in three skin cellular models: Effects of sonication, dispersive agents and corneous layer of reconstructed epidermis. Nanotoxicology 2010, 4, 84-97.

51. Sargent, L.M.; Reynolds, S.H.; Castranova, V. Potential pulmonary effects of engineered carbon nanotubes: In vitro genotoxic effects. Nanotoxicology 2010, 4, 396-408. 
52. Naya, M.; Kobayashi, N.; Mizuno, K.; Matsumoto, K.; Ema, M.; Nakanishi, J. Evaluation of the genotoxic potential of single-wall carbon nanotubes by using a battery of in vitro and in vivo genotoxicity assays. Regul. Toxicol. Pharmacol. 2011, 61, 192-198.

53. Magrez, A.; Kasas, S.; Salicio, V.; Pasquier, N.; Seo, J.W.; Celio, M.; Catsicas, S.; Schwaller, B.; Forro, L. Cellular toxicity of carbon-based nanomaterials. Nano Lett. 2006, 6, 1121-1125.

54. Jacobsen, N.R.; Pojana, G.; White, P.; Moller, P.; Cohn, C.A.; Korsholm, K.S.; Vogel, U.; Marcomini, A.; Loft, S.; Wallin, H. Genotoxicity, cytotoxicity, and reactive oxygen species induced by single-walled carbon nanotubes and $\mathrm{C}(60)$ fullerenes in the FE1-Mutatrade markMouse lung epithelial cells. Environ. Mol. Mutagen. 2008, 49, 476-487.

55. Di Sotto, A.; Chiaretti, M.; Carru, G.A.; Bellucci, S.; Mazzanti, G. Multi-walled carbon nanotubes: Lack of mutagenic activity in the bacterial reverse mutation assay. Toxicol. Lett. 2009, 184, 192-197.

56. Nagai, H.; Okazaki, Y.; Chew, S.H.; Misawa, N.; Yamashita, Y.; Akatsuka, S.; Ishihara, T.; Yamashita, K.; Yoshikawa, Y.; Yasui, H.; et al. Diameter and rigidity of multiwalled carbon nanotubes are critical factors in mesothelial injury and carcinogenesis. Proc. Natl. Acad. Sci. USA 2011, 108, E1330-E1338.

57. Shvedova, A.A.; Kisin, E.; Murray, A.R.; Johnson, V.J.; Gorelik, O.; Arepalli, S.; Hubbs, A.F.; Mercer, R.R.; Keohavong, P.; Sussman, N.; et al. Inhalation vs. aspiration of single-walled carbon nanotubes in C57BL/6 mice: Inflammation, fibrosis, oxidative stress, and mutagenesis. Am. J. Physiol. Lung Cell. Mol. Physiol. 2008, 295, L552-L565.

58. Shvedova, A.A.; Kisin, E.R.; Mercer, R.; Murray, A.R.; Johnson, V.J.; Potapovich, A.I.; Tyurina, Y.Y.; Gorelik, O.; Arepalli, S.; Schwegler-Berry, D.; et al. Unusual inflammatory and fibrogenic pulmonary responses to single-walled carbon nanotubes in mice. Am. J. Physiol. Lung Cell. Mol. Physiol. 2005, 289, L698-L708.

59. Johnston, H.J.; Hutchison, G.R.; Christensen, F.M.; Peters, S.; Hankin, S.; Aschberger, K.; Stone, V. A critical review of the biological mechanisms underlying the in vivo and in vitro toxicity of carbon nanotubes: The contribution of physico-chemical characteristics. Nanotoxicology 2010, 4, 207-246.

60. Donaldson, K.; Murphy, F.; Schinwald, A.; Duffin, R.; Poland, C.A. Identifying the pulmonary hazard of high aspect ratio nanoparticles to enable their safety-by-design. Nanomedicine 2011, 6, 143-156.

61. Donaldson, K.; Murphy, F.A.; Duffin, R.; Poland, C.A. Asbestos, carbon nanotubes and the pleural mesothelium: A review of the hypothesis regarding the role of long fibre retention in the parietal pleura, inflammation and mesothelioma. Part. Fibre Toxicol. 2010, 7, 5.

62. Migliore, L.; Saracino, D.; Bonelli, A.; Colognato, R.; D’Errico, M.R.; Magrini, A.; Bergamaschi, A.; Bergamaschi, E. Carbon nanotubes induce oxidative DNA damage in RAW 264.7 cells. Environ. Mol. Mutagen. 2010, 51, 294-303.

63. Vittorio, O.; Raffa, V.; Cuschieri, A. Influence of purity and surface oxidation on cytotoxicity of multiwalled carbon nanotubes with human neuroblastoma cells. Nanomedicine 2009, 5, 424-431.

64. Dostert, C.; Petrilli, V.; Van Bruggen, R.; Steele, C.; Mossman, B.T.; Tschopp, J. Innate immune activation through Nalp3 inflammasome sensing of asbestos and silica. Science 2008, 320, 674-677. 
65. Palomaki, J.; Valimaki, E.; Sund, J.; Vippola, M.; Clausen, P.A.; Jensen, K.A.; Savolainen, K.; Matikainen, S.; Alenius, H. Long, needle-like carbon nanotubes and asbestos activate the NLRP3 inflammasome through a similar mechanism. ACS Nano 2011, 5, 6861-6870.

66. Yang, S.T.; Wang, X.; Jia, G.; Gu, Y.; Wang, T.; Nie, H.; Ge, C.; Wang, H.; Liu, Y. Long-term accumulation and low toxicity of single-walled carbon nanotubes in intravenously exposed mice. Toxicol. Lett. 2008, 181, 182-189.

67. Wick, P.; Manser, P.; Limbach, L.K.; Dettlaff-Weglikowska, U.; Krumeich, F.; Roth, S.; Stark, W.J.; Bruinink, A. The degree and kind of agglomeration affect carbon nanotube cytotoxicity. Toxicol. Lett. 2007, 168, 121-131.

68. Murray, A.R.; Kisin, E.; Leonard, S.S.; Young, S.H.; Kommineni, C.; Kagan, V.E.; Castranova, V.; Shvedova, A.A. Oxidative stress and inflammatory response in dermal toxicity of single-walled carbon nanotubes. Toxicology 2009, 257, 161-171.

69. Aschberger, K.; Johnston, H.J.; Stone, V.; Aitken, R.J.; Hankin, S.M.; Peters, S.A.; Tran, C.L.; Christensen, F.M. Review of carbon nanotubes toxicity and exposure-Appraisal of human health risk assessment based on open literature. Crit. Rev. Toxicol. 2010, 40, 759-790.

70. Ai, J.; Biazar, E.; Jafarpour, M.; Montazeri, M.; Majdi, A.; Aminifard, S.; Zafari, M.; Akbari, H.R.; Rad, H.G. Nanotoxicology and nanoparticle safety in biomedical designs. Int. J. Nanomed. 2011, 6, 1117-1127.

71. Stefani, D.; Paula, A.J.; Vaz, B.G.; Silva, R.A.; Andrade, N.F.; Justo, G.Z.; Ferreira, C.V.; Filho, A.G.; Eberlin, M.N.; Alves, O.L. Structural and proactive safety aspects of oxidation debris from multiwalled carbon nanotubes. J. Hazard Mater. 2011, 189, 391-396.

72. Rourke, J.P.; Pandey, P.A.; Moore, J.J.; Bates, M.; Kinloch, I.A.; Young, R.J.; Wilson, N.R. The real graphene oxide revealed: Stripping the oxidative debris from the graphene-like sheets. Angew. Chem. Int. Ed. Engl. 2011, 50, 3173-3177.

73. Fogden, S.; Verdejo, R.; Cottam, B.; Shaffer, M. Purification of single walled carbon nanotubes: The problem with oxidation debris. Chem. Phys. Lett. 2008, 460, 162-167.

74. Ryman-Rasmussen, J.P.; Cesta, M.F.; Brody, A.R.; Shipley-Phillips, J.K.; Everitt, J.I.; Tewksbury, E.W.; Moss, O.R.; Wong, B.A.; Dodd, D.E.; Andersen, M.E.; et al. Inhaled carbon nanotubes reach the subpleural tissue in mice. Nat. Nanotechnol. 2009, 4, 747-751.

75. Kagan, V.E.; Konduru, N.V.; Feng, W.; Allen, B.L.; Conroy, J.; Volkov, Y.; Vlasova, I.I.; Belikova, N.A.; Yanamala, N.; Kapralov, A.; et al. Carbon nanotubes degraded by neutrophil myeloperoxidase induce less pulmonary inflammation. Nat. Nanotechnol. 2010, 5, 354-359.

76. Liu, X.; Hurt, R.H.; Kane, A.B. Biodurability of single-walled carbon nanotubes depends on surface functionalization. Carbon 2010, 48, 1961-1969.

77. Yamashita, K.; Yoshioka, Y.; Higashisaka, K.; Morishita, Y.; Yoshida, T.; Fujimura, M.; Kayamuro, H.; Nabeshi, H.; Yamashita, T.; Nagano, K.; et al. Carbon nanotubes elicit DNA damage and inflammatory response relative to their size and shape. Inflammation 2010, 33, 276-280.

78. Coccini, T.; Roda, E.; Sarigiannis, D.A.; Mustarelli, P.; Quartarone, E.; Profumo, A.; Manzo, L. Effects of water-soluble functionalized multi-walled carbon nanotubes examined by different cytotoxicity methods in human astrocyte D384 and lung A549 cells. Toxicology 2010, 269, 41-53. 
79. Nabeshi, H.; Yoshikawa, T.; Matsuyama, K.; Nakazato, Y.; Matsuo, K.; Arimori, A.; Isobe, M.; Tochigi, S.; Kondoh, S.; Hirai, T.; et al. Systemic distribution, nuclear entry and cytotoxicity of amorphous nanosilica following topical application. Biomaterials 2011, 32, 2713-2724.

80. Nabeshi, H.; Yoshikawa, T.; Matsuyama, K.; Nakazato, Y.; Tochigi, S.; Kondoh, S.; Hirai, T.; Akase, T.; Nagano, K.; Abe, Y.; et al. Amorphous nanosilica induce endocytosis-dependent ROS generation and DNA damage in human keratinocytes. Part. Fibre Toxicol. 2011, 8, 1.

81. Nabeshi, H.; Yoshikawa, T.; Arimori, A.; Yoshida, T.; Tochigi, S.; Hirai, T.; Akase, T.; Nagano, K.; Abe, Y.; Kamada, H.; et al. Effect of surface properties of silica nanoparticles on their cytotoxicity and cellular distribution in murine macrophages. Nanoscale Res. Lett. 2011, 6, 93.

82. Lundqvist, M.; Stigler, J.; Elia, G.; Lynch, I.; Cedervall, T.; Dawson, K.A. Nanoparticle size and surface properties determine the protein corona with possible implications for biological impacts. Proc. Natl. Acad. Sci. USA 2008, 105, 14265-14270.

83. Sund, J.; Alenius, H.; Vippola, M.; Savolainen, K.; Puustinen, A. Proteomic characterization of engineered nanomaterial-protein interactions in relation to surface reactivity. ACS Nano 2011, 5, 4300-4309.

84. Gasser, M.; Rothen-Rutishauser, B.; Krug, H.F.; Gehr, P.; Nelle, M.; Yan, B.; Wick, P. The adsorption of biomolecules to multi-walled carbon nanotubes is influenced by both pulmonary surfactant lipids and surface chemistry. J. Nanobiotechnol. 2010, 8, 31.

85. Moghimi, S.M.; Hunter, A.C. Complement monitoring of carbon nanotubes. Nat. Nanotechnol. 2010, 5, 382.

(C) 2012 by the authors; licensee MDPI, Basel, Switzerland. This article is an open access article distributed under the terms and conditions of the Creative Commons Attribution license (http://creativecommons.org/licenses/by/3.0/). 